\title{
KEGIATAN PENDAMPINGAN PERANCANGAN FASILITAS UMUM KOMPLEKS KAVLING SIDOMAKMUR BARU, DESA MULYOAGUNG, KECAMATAN DAU KABUPATEN MALANG
}

\author{
Bayu Teguh Ujianto \\ Dosen Prodi Arsitektur, Fak. Teknik Sipil dan Perencanaan, ITN Malang \\ e-mail: bayu teguh@lecturer.itn.ac.id \\ Tutut Nani Prihatmi \\ Dosen Prodi Teknik Mesin, Fak. Teknologi Industri, ITN Malang \\ e-mail: tutut.nani@lecturer.itn.ac.id
}

\begin{abstract}
ABSTRAK
Keberadaan fasilitas umum lingkungan sangat dibutuhkan pada komplek permukiman di Jl. Sidomakmur Baru ini, karena hal tersebut merupakan kelengkapan dasar fisik lingkungan yang memungkinkan lingkungan dapat berfungsi sebagaimana mestinya. Suatu lingkungan kavling yang merupakan permukiman membutuhkan jaringan jalan untuk mobilitas orang dan angkutan barang, serta untuk menciptakan ruang dan bangunan yang teratur. Perancangan fasilitas umum di Jl. Sidomakmur Baru ini, diharapkan mampu memberikan konstribusi yang nyata kepada warga, mengingat kurangnya fasilitas umum tersebut menimbulkan kondisi yang negatif pada lingkungan dan tidak adanya lampu jalan membuat wilayah tersebut rawan pencurian, akses jalan yang banyak mendorong warga untuk membangun gerbang masuk kawasan, balai pertemuan warga, lampu jalan, lanskap pembatas kawasan, pagar tembok pembatas kawasan dan fasilitas umum penunjang lainnya. Metode pendekatan yang digunakan untuk menyelesaikan permasalahan kegiatan adalah, metode diskusi dan sosialisasi, metode observasi dan analisis data, dan metode partisipasi sosial. Ketiga jenis pendekatan tersebut diharapkan mampu merangkul semua pihak terkait untuk bekerjasama mewujudkan program kegiatan ini, agar dapat bermanfaat bagi warga pada khususnya warga Kavling Sidomakmur Baru dan warga sekitarnya pada umumnya.
\end{abstract}

Kata kunci: Perancangan, Kavling, Fasilitas Umum.

\section{ABSTRACT}

The existence of environmental facilities is very much needed at the housing complex on Jl. Sidomakmur Baru, because it is the basic physical completeness of environment that allows the environment to function properly. A plot environment used as a housing requires a road system for people's mobility and freight transportation, as 
well as to create regular spaces and buildings. The design of public facilities on Jl. Sidomakmur Baru is expected to be able to provide a real contribution to its residents, given the lack of public facilities that cause negative conditions on the environment. The absence of street lights allow this area prone to theft, road accesses encourage many people to build distric gates, community meeting halls, street lights, boundary landscapes, boundary walls and other supporting public facilities. The method of approach used to solve the problem of activities is the method of discussion and socialization, methods of observation and data analysis, and methods of social participation. The three types of approaches are expected to be able to embrace all relevant parties to work together to create the activity program, therefore it can be useful for all the residents especially those in Sidomakmur Baru plots and the residents around in general.

Keywords: Design, Plot, Public Facilities.

\section{PENDAHULUAN}

Awal dibentuknya Komplek Kavling Sidomakmur Baru ini, berasal dari tanah sawah dan perkebunan warga setempat yang kemudian dijual bertahap kepada warga lain. Lambat laun pembeli atau pemilik kavling tersebut mulai membangun tanah kavling mereka menjadi rumah tinggal. Jalan akses utama pertama kali dibentuknya tanah kavling ini berupa jalan makadam, dan seiring berjalannya waktu dan bertambahnya penduduk baru mereka bergotong royong dengan dana pribadi untuk memperbaiki jalan makadam tersebut. Dengan kerja keras dan rasa gotong royong warganya, saat ini telah terbangun jalan paving yang selesai pada tahun 2016. Hasil pembangunan Paving tersebut sangat membantu warga lain menuju tanah garapannya berupa sawah maupun perkebunan.

Saat ini jumlah Kavling pada Komplek Kavling Sidomakmur Baru ini berjumlah 39 kavling dan telah terbangun 22 rumah dengan 22 Kepala Keluarga. Berikut ini adalah gambar siteplan Komplek Kavling Sidomakmur Baru. 


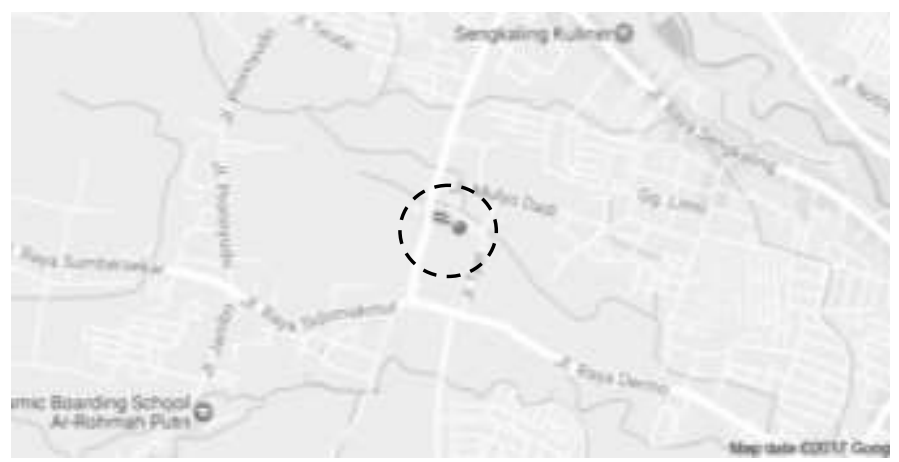

Gambar. 1

Peta Lokasi Komplek Kavling Sidomakmur Baru Sumber: Google Map, 2018

Berdasarkan keterangan responden pada bulan tertentu tindakan pencurian meningkat. Selain itu, warga Komplek Kavling tersebut mengeluhkan para tamu ataupun jasa pengantar barang mereka kesulitan mencari alamat jalan. Sehingga, untuk tahapan kedepannya mereka berencana akan membangun sebuah gapura yaitu berupa desain gerbang masuk kawasan. Selain itu, untuk kedepannya akan dibangun balai pertemuan warga, lampu jalan, lanskap pembatas kawasan.

Dalam kegiatan Pendampingan ini, perlu terciptanya konsep desain yang efisien dan tepat guna. Sehingga, fasilitas umum yang akan didesain dan dirancang diharapkan dapat terbangun sesuai konsep desain yang akan dikeluarkan. Sebenarnya, warga Komplek Kavling tersebut memiliki dana yang terbatas. Karena, dana yang dikumpulkan merupakan hasil dari swadaya warga Komplek Kavling sendiri. Warga Komplek Kavling Sidomakmur Baru berharap agar hasil keluaran desain perencanaan fasilitas umum mudah diterapkan pada komplek kavling mereka. Sehingga gambar produk perancangan fasilitas umum dapat dijadikan sebagai acuan bagi

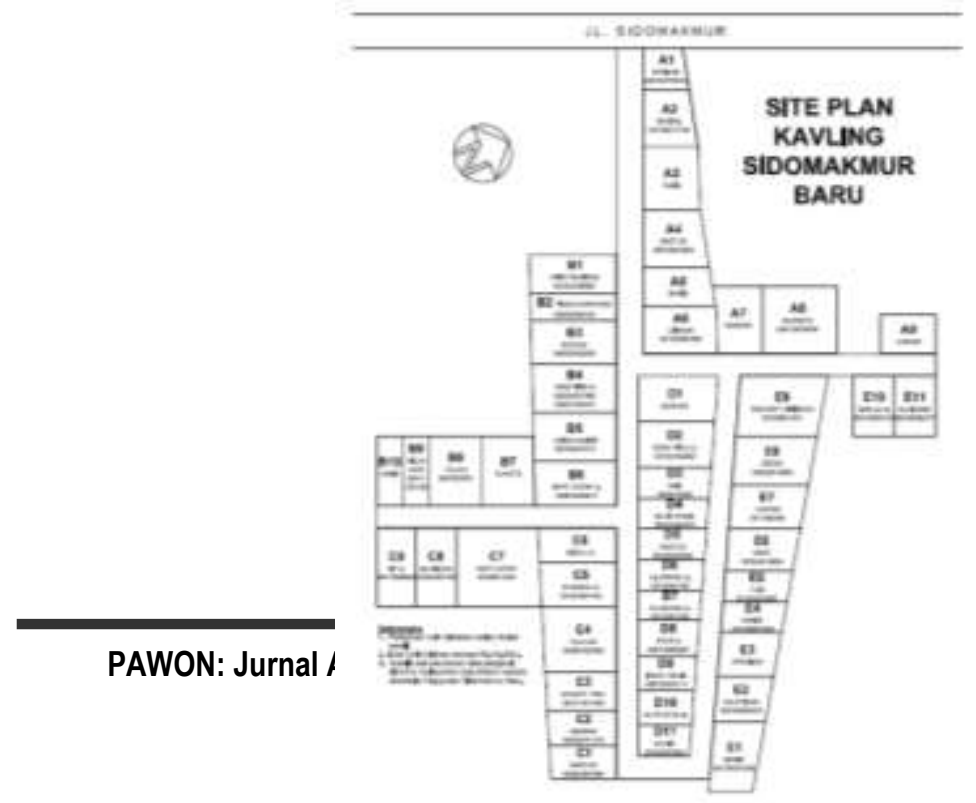

9, ISSN 2597-7636 
warga Komplek Kavling untuk membangun desain gerbang masuk kawasan, balai pertemuan warga, lampu jalan, lanskap pembatas kawasan yang baik dari segi pemanfaatan dan keindahan serta sebagai acuan bagi warga Komplek Kavling Sidomakmur Baru. Penerapan ilmu Arsitektur ini akan sangat membantu warga Komplek Kavling tersebut dalam mencapai estetika sebuah bentuk dan fungsinya. 


\section{TINJAUAN PUSTAKA}

Berdasarkan analisis situasi dan permasalahan masyarakat, maka solusi yang ditawarkan adalah sebagai berikut:

\section{Desain Gerbang Masuk Kawasan / Gapura}

Menurut KBBI gapura adalah pintu besar untuk masuk pekarangan rumah (jalan, taman, dan sebagainya); pintu gerbang; kehormatan gapura (pintu gerbang) yang dibuat sebagai tanda atau pernyataan hormat (untuk menghormati tamu, peristiwa penting, dan sebagainya). Ide pembuatan desain gapura ini, diperlukan untuk menjawab permasalahan mengenai identitas wilayah terkait Mitra 2 warga Komplek Kavling Sidomakmur Baru dan permasalahan yang muncul karena tidak adanya identitas komplek kavling.

Berdasarkan pada hasil diskusi antara tim pengusul dan mitra maka disepakai bahwa gapura yang akan diterapkan adalah gapura yang mampu mewakili identitas wilayah dan kepribadian warga Komplek Kavling Sidomakmur Baru yang mampu dicerna dan dipahami oleh warga sekitarnya.

\section{Desain Balai Pertemuan Warga}

Balai pertemuan warga adalah tempat berapat, pernikahan dan kegiatan lain yang dapat digunakan dengan semestinya.

\section{Desain Lampu Penerangan}

Lampu jalan adalah lampu yang digunakan untuk penerangan jalan dimalam hari sehingga pejalan kaki, pesepeda dan pengendara dapat melihat dengan lebih jelas jalan yang akan dilalui pada malam hari, sehingga dapat meningkatkan keselamatan lalu lintas dan keamanan dari para pengguna jalan. Berdasarkan permasalahan diatas, diharapkan Ide desain lampu penerangan jalan ini, mampu memberikan nilai estetika yang indah dan efisiensi penggunaan konsumsi listrik pada malam hari.

\section{Desain Lanskap Pembatas Kawasan}

Arsitektur lanskap adalah bidang ilmu (science) dan seni (art) yang mempelajari pengaturan ruang dan massa di alam terbuka, dengan mengkombinasikan elemen-elemen lanskap alami ataupun buatan manusia, baik secara horizontal maupun vertikal, dengan segenap kegiatannya, agar tercipta karya lingkungan yang secara fungsional berguna dan secara estetika tetap indah. 


\section{Desain Pagar Pembatas Kawasan}

Dekorasi tempat tinggal ternyata tidak hanya pada ruangan saja, tetapi juga bisa dilakukan pada bagian pagar termasuk pagar pembatas kawasan. Fungsi dari pagar sesungguhnya adalah sebagai pembatas dan juga pengaman rumah. Namun seiring dengan berjalannya waktu, fungsi pagar beralih menjadi elemen yang dapat menambah suatu estetika.

6. Desain Fasilitas Umum Lainnya

Desain fasum lainnya yang dimaksud adalah desain rancang yang sifatnya accidental di lapangan. Misalnya desain saluran air, pos satpam, dll.

Ide desain tersebut diatas, nantinya akan dilakukan dengan bekerjasama dengan berbagai mitra terkait yang turut mendukung program kegiatan yang diusulkan sangat diharapkan sebagai upaya perwujudan program kegiatan pengabdian kepada masyarakat ini.

\section{METODE PENELITIAN}

Metode pendekatan yang digunakan untuk menyelesaikan permasalahan kegiatan adalah, sebagai berikut:

a. Metode pendekatan diskusi

Metode pendekatan diskusi digunakan pada saat sosialisasi tahap awal kegiatan untuk mendapatkan kesepakatan bersama antara Tim Pengusul, Mitra, dan Perwakilan Warga mengenai ide, lokasi dan konsep terkait rencana kegiatan Program Pengabdian Masyarakat ini. Tahap diskusi selanjutnya dilakukan pada saat penyusunan konsep dan desain rancangan berdasarkan data yang di peroleh, kemudian tahap diskusi selanjutnya dilakukan pada saat sosialisasi produk desain ke warga sehingga didapatkan masukan jika ada tambahan ide yang dapat ditambahkan.

b. Observasi data dan analisis

Metode observasi dan analisis data ini digunakan untuk merencanakan dan membuat konsep desain. Observasi lapangan diperlukan untuk mengetahui data dan kondisi eksisting lokasi penempatan lampu jalan, pos satpam dan saluran pembuangan air. Observasi data terkait yang akan digunakan untuk dianalisis oleh tim pengusul dan mitra sebagai dasar untuk menentukan konsep dan desain sarana prasarana di Komplek Kavling Sidomakmur Baru

c. Metode pendekatan partisipasi

Metode pendekatan partisipasi ini dilakukan untuk memberdayakan potensi warga, bekerjasama dengan tim pengusul dan mitra beserta beberapa mahasiswa dari perguruan tinggi tim pengusul. Hal ini dilakukan

PAWON: Jurnal Arsitektur, Nomor 02 Volume III, Januari-Juni 2019, ISSN 2597-7636 
untuk tetap menjaga karakter kegotongroyongan warga. Pendekatan partisipasi ini dilaksanakan pada saat proses pengadaan dan pembuatan sarana dan prasarana.

Ketiga jenis pendekatan tersebut diharapkan mampu merangkul semua pihak terkait untuk bekerjasama mewujudkan program kegiatan ini, agar dapat bermanfaat bagi warga Kelurahan Mulyoagung pada khususnya warga Komplek Kavling Sidomakmur Baru.

\section{HASIL DAN PEMBAHASAN}

Analisa perancangan fasilitas umum kompleks kavling Sidomakmur Baru ini, akan dibagi menjadi beberapa bagian yaitu Bagian A (Sign in, Pos Jaga dan Taman), Bagian B (Pagar Pembatas), Bagian C (Balai Warga), Bagian C (Taman Bermain dan Berkumpul). Berikut ini adalah pembahasan analisa perancangan fasilitas umum kompleks Sidomakmur Baru.

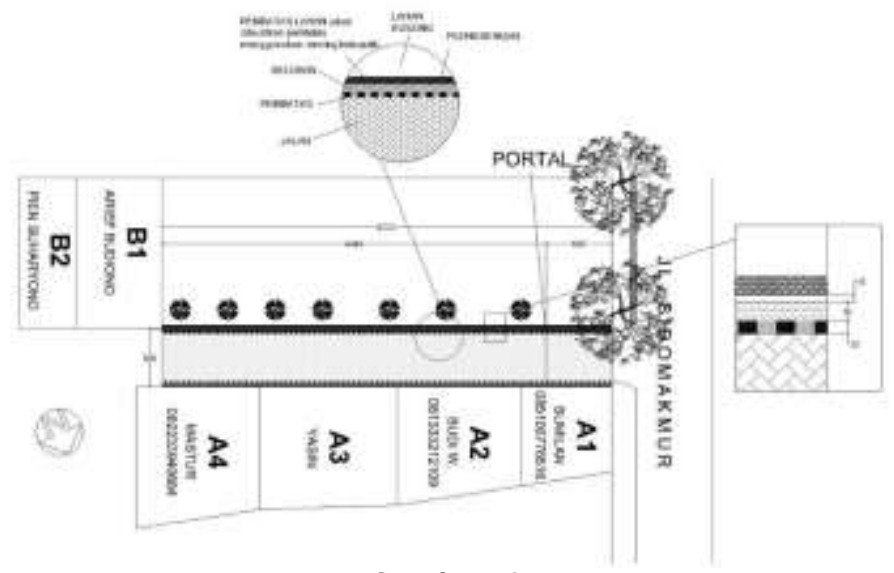

Gambar. 1

Eksisting Tapak A

Sumber: Ujianto, 2018

Kendaraan yang akan masuk ke lingkungan sidomakmur baru dari arah selatan saat ini sedikit kesulitan dengan keadaan jalan yang cukup miring. Dengan keadaan topografi a-a yang sedemikian rupa, maka untuk selokan/sistem drainase pada bagian sebelah timur tidak berfungsi dengan maksimal. Dikarenakan kemiringan tersebut justru membuat arah pembuangan akan berlawanan dengan sistem drainase kota yang ada di sebelah barat. Solusi permasalahan tersebut antara lain:

a) Untuk bagian drainase/selokan di sebelah timur bisa ditimbun kembali dengan tanah dan dimanfaatkan sebagai taman. 
b) Untuk bagian drainase/selokan di sebelah barat bisa ditimbun kembali dengan tanah dan dimanfaatkan sebagai taman. Namun tetap diberikan space sedikit untuk sistem pembuangan.

c) Penerapan teknik fill pada area yang dijadikan Pos Jaga.

Sedangkan Pos Jaga ditempatkan di sisi selatan jalan Sidomakmur Baru dan berada 5,4meter ketimur dari portal (titik akhir pos jaga berada pada jarak 35meter dari rumah Kav. B.
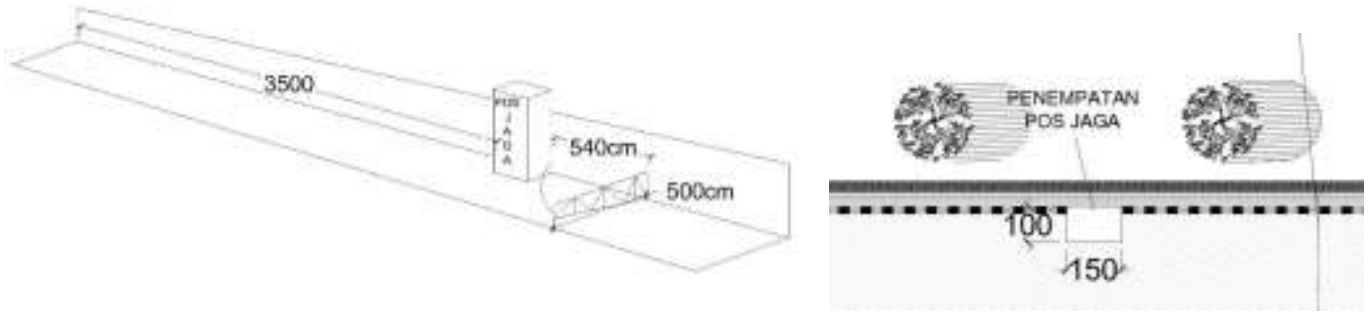

Gambar. 2

Rencana penempatan pos jaga

Sumber: Ujianto, 2018

Sign in ditempatkan dibagian depan jalan sidomakmur baru, tepatnya disisi selatan.ini dimaksudkan untuk memberikan identitas pada lingkungan ini.dan memudahkan orang-orang untuk membaca sign in ini.

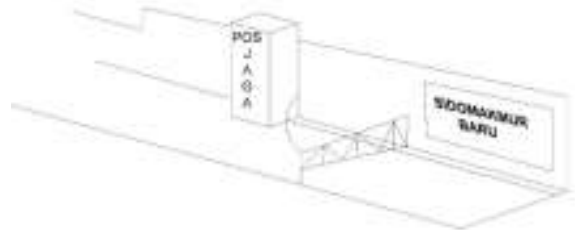

Gambar. 3

Rencana penempatan Sign in

Sumber: Ujianto, 2018

Plengsengan yang terlihat tidak rapi dan cenderung kotor pada lahan kosong akan sedikit mengganggu view to site. Plengsengan dibagian depan jalan sidomakmur baru cukup tinggi. Sehingga view to site ke Pos Jaga, taman dan sign in akan terasa sulit bagi kendaraan dari arah selatan. Pada tembok yang setinggi $150 \mathrm{~cm}$, menggunakan kombinasi antara bata putih dan roster disusun dengan bentuk variatif agar tidak terlihat monoton. Untuk mengarahkan pengendara, pada taman yang berada disepanjang sisi selatan jalan Sidomakmur Baru menggunakan tanaman pengarah. 

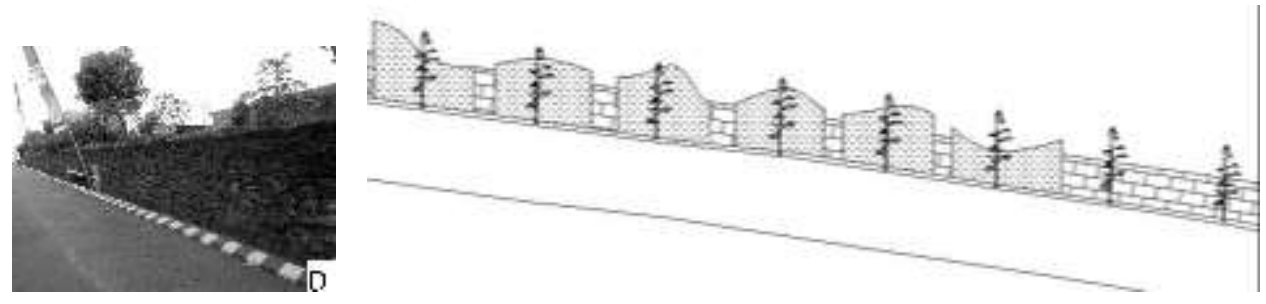

Gambar. 4

Tanaman pengarah

Sumber: Ujianto, 2018

Untuk sign in menggabungkan 2 tipe sign in yaitu dengan sign in background dan juga tanpa sign in background.

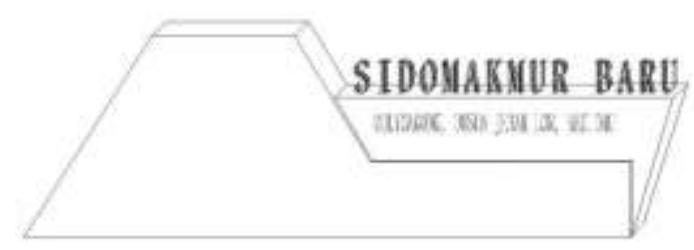

Gambar. 5

Konsep sign in

Sumber: Ujianto, 2018

Untuk mengantisipasi sinar matahari langsung, tanaman rambat ditempatkan di sisi timur pos jaga. Ini dimaksudkan untuk melindungi Pos Jaga dari sinar matahari secara langsung pada pagi hari. Untuk arah hadap yaitu arah barat, hal tersebut dimaksudkan untuk memberikan tangkapan pada bangunan Pos Jaga ini. Patahan pada atap yang tadinya berada ditengah akan didorong kearah barat sehingga lebih condong ke arah barat. Maka dengan demikian bangunan ini nantinya akan menghadap kearah barat walaupun entrance berada disisi timur. Dan nantinya akan ada permainan finishing sebagai nilai tambah pada sisi barat sebagai point of interest tersendiri.

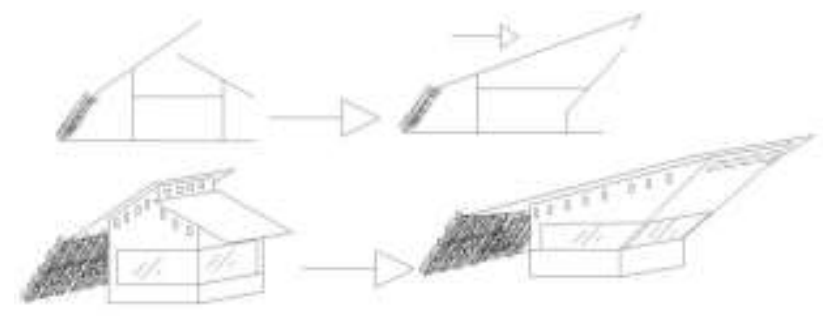

Gambar. 6

Sketsa sisi pos jaga

Sumber: Ujianto, 2018

PAWON: Jurnal Arsitektur, Nomor 02 Volume III, Juli-Desember 2019, ISSN 2597-7636 
Untuk lahan bagian timur mulai dari ujung tanah Kav.B1 sampai titik 26.5meter ditemui selokan yang nantinya akan ditutup sepenuhnya menggunakan tanah gembur dan kemudian diberi rumput gajah mini. Sehingga, nantinya akan ditanam tanaman pengarah berukuran besar dan kecil. Selokan ini ditutup karena tidak berfungsi secara maksimal.

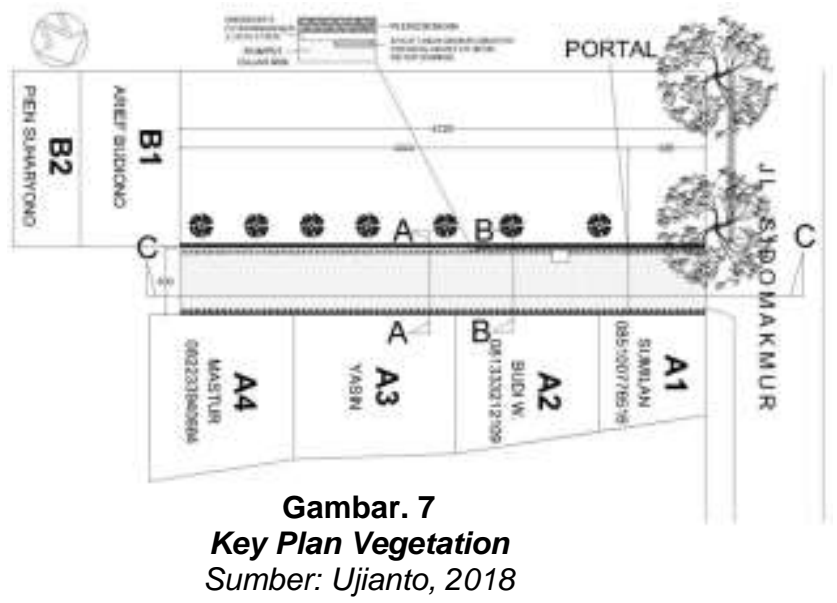

Pada bagian timur akan ditanami pohon pengarah, yakni cemara kipas dengan jarak masing-masing 3meter berjumlah 11 pohon. Diantara pohon pengarah akan dibuatkan beberapa rangka seperti pagar. Hal ini bertujuan ini sebagai rangka tanaman vertical garden dan untuk lampu taman akan menggunakan lampu taman tipe standing (Philips bcp650 (200mm) Bollard Led Lampu Taman).
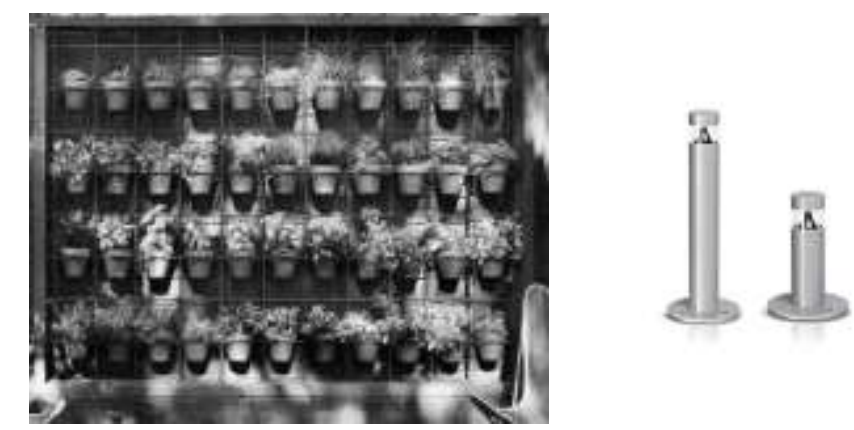

Gambar. 8

Contoh vertical garden dan standing lamp yang dapat diterapkan

Sumber: arsitag.com 
Tembok pembatas yang dijadikan sebagai background taman dan vertical garden dikombinasikan dengan batu bata putih setinggi $50 \mathrm{~cm}$ pada bagian bawah dan sisanya pada bagian atas menggunakan roster yang disusun secara variative sehingga dapat menciptakan dinding yang unik dan tidak monoton.

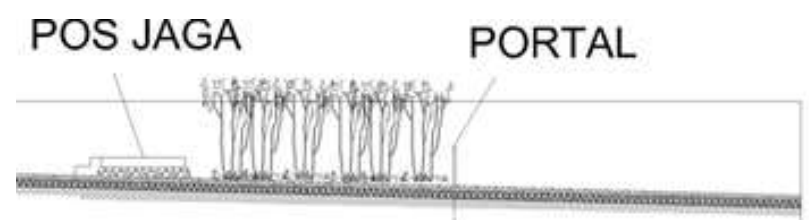

Gambar. 9

Jarak vegetasi terhadap portal

Sumber: Ujianto, 2018

Bagian dari pandangan View 1 dimaksimalkan untuk memunculkan point of interst dari tapak, dengan banyak permainan elemen - elemen yang ada. Kemudian untuk membantu penerangan pada malam hari digunakan lampu (solar lantem n760a light motion). Lampu taman dengan jenis temple atau tanam. Sedangkan. desain pagar agar tidak menonton maka akan di buat permainan antara bata putih dan roster seperti contoh dibawah ini. Serta bagaimana pengaplikasian tanaman pada desain nantinya.

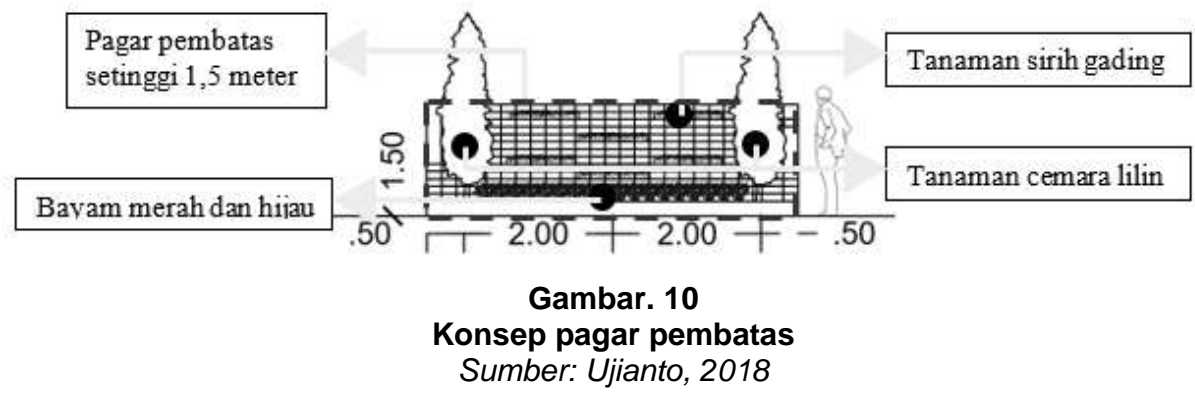

Untuk elemen - elemen yang ingin di ciptakan antara lain:

- Titik, dari bagian yang maju atau di mundurkan dari batu bata atau rosternya.

- Garis, bagian rata pagar horizontal dan vertical, kemudian kolom yang ada.

- Bidang, bidang nayata pada pagar itu sendiri, kemudian bidang semu dari frame semu yang di buat pagar dan tanaman cemara lilin yang membatasi.

- Warna, warna banyak adalah netral bahan bata putih dan roster yang di expose. Dan tanaman yang ada seperti warna hijau, merah dan hijau ke kuningan. 
- Pola, pola yang terbentuk dari permainan bata putih dan roster yang ada.

- Irama, terdapat pada permainan pola yang berulang dan penyusunan tanaman yang ada.

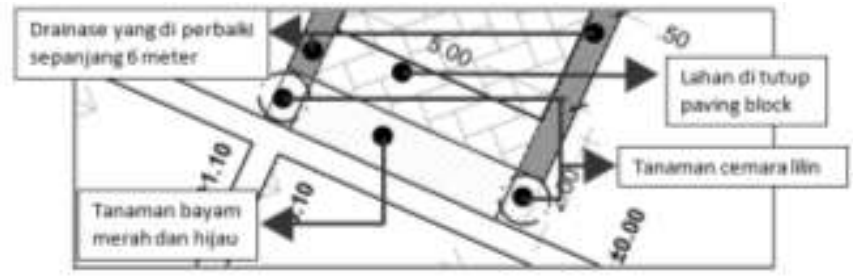

Gambar. 11

Rencana penempatan vegetasi pada tapak skala 1:100

Sumber: Ujianto, 2018

\section{KESIMPULAN}

Dalam analisa yang telah dijabarkan diatas, telah dibahas beberapa kendala dan solusi dari masing - masing fasilitas umum yang nantinya akan didesain. Masing- masing analisa telah dijabarkan sesuai dengan survei lokasi pada tapak. Sehingga, didapatkan beberapa konsep perancangan yang nantinya akan menghasilkan desain fasilitas umum pada kegiatan pendampingan tahap 2 atau lanjutan.

Kerjasama antar warga yang berupa diskusi tentang fasilitas umum apa saja yang dibutuhkan pada kompleks kavling Sidomamur ini, menjadikan dasar pemilihan fasilitas umum apa saja yang akan didesain dan diterapkan dengan baik pada kompleks kavling Sidomakmur Baru. Masalah yang muncul dalam perancangan fasilitas umum nantinya akan terselesaikan dengan baik, sehingga dapat bermanfaat bagi masyarakat khususnya warga kavling Sidomakmur Baru.

\section{DAFTAR PUSTAKA}

Kep. Men. PU no. 468/KPTS/1998, Persyaratan Teknis Aksesibilitas pada Bangunan Umum dan Lingkungan, ICS 91.020; 91.040.30 . Badan Standardisasi Nasional.

Adrianto, Bowo, 2006, Persepsi Dan Partisipasi Masyarakat Terhadap Pembangunan Prasarana Dasar Permukiman Yang Bertumpu Pada Swadaya Masyarakat $\mathrm{Di}$ Kota Magelang. Semarang. Program Pascasarjana Magister Pembangunan Wilayah Dan Kota Universitas Diponegoro.

Adisasmita, Rahardji, 2010, Analisis Tata Ruang Pembangunan, Yogyakarta: Graha IImu. 
Koestoer H. R. 1997. Perspektif Lingkungan Desa - Kota. Jakarta Penerbit Universitas Indonesia.

Anonym. Teori Kota dan Citra Kota.

http://e-journal.uajy.ac.id/482/3/2MTA01479.pdf

Abdil, M. (2012). Penelitian Penggunaan Lampu Flourescent (TL) dan Lampu

Pijar

(Wolfram).http://margionoabdil.blogspot.com/2012/11/penelitian penggunaanlampu-tl-dan.html. 15 Agustus 2014.

https://www.kompasiana.com/azkaazra/sekilas-tentang-arsitekturlanskap_54f72bcca33311ea6a8b46bf 